\title{
DALE AND THE DEVELOPMENT OF PHARMACOLOGY
}

Lecture given at Sir Henry Dale Centennial Symposium, Cambridge, 17-19 September 1975

H.O. SCHILD

Department of Pharmacology, University College, London
The title of my lecture, 'Dale and the development of pharmacology', seems entirely appropriate in view of Dale's fundamental contributions to the subject; but it also contains a paradoxical element since Dale did not really consider himself a pharmacologist. He considered himself a physiologist, as he was by training and inclination. He trained in physiology with Langley and Gaskell in Cambridge, and after completing his medical course at Barts continued working as a physiologist with Starling as Sharpey Scholar. When at the age of 29 he became a pharmacologist by joining the Wellcome laboratories, he did not seem entirely happy at the transition, as is apparent from his writings in which he refers to the ergot 'morass' which he had entered, although he extracted some marvellous nuggets from it.

Dale was atypical in his attitude of cautious reserve towards the drug receptor idea which has become so dominant a feature of pharmacology. He did not explain in terms of receptors the adrenaline reversal by ergot and although he knew of Langley's postulated 'receptive substances' he tended to emphasize our total ignorance of their nature. Interestingly though, in his 1919 Croonian Lecture he argued that the one receptive substance of which we knew something (because it could be studied apart from the cell) was the anaphylactic antibody, suggesting that its reaction with a specific antigen might provide an opportunity of studying drug-receptor interactions in a 'test tube'.

On a deeper level, Dale at times seemed almost surprised at the long range pharmacological-medical implications of his own discoveries. On one occasion, when discussing the early clinical uses of ganglion blocking drugs in hypertension he expressed astonishment that a symptomatic drug could be so effective in a chronic disease, probably reflecting the philosophy of Ehrlich who distinguished sharply between symptomatic and causal drugs. Yet, we know now from statistical evidence that treating the symptom hypertension, prolongs life.

It can be said of Dale, as indeed of Ehrlich, that he was one of the great originators of pharmacology rather than a typical pharmacologist. Such people, by their very power and originality, cannot readily be accommodated within the framework of a restricted subject, though Dale's work is bound to exert a deep and lasting influence on the development and future of pharmacology.

\section{Dale's laboratory}

Dale's great discoveries were made with a few selected coworkers and assistants in the atmosphere of the typical old fashioned physiological laboratory, having the smoked drum as its mainstay. I would like to recall the impression he made on a young pharmacologist of little experience entering his laboratory for the first time. When I joined Dale in 1932 I had been working for a short while with Straub, a German pharmacologist concerned at that time with gastrointestinal pharmacology. Entering Dale's laboratory from Straub's, one had the impression of coming in from the periphery and entering the centre. Every problem tackled in Dale's laboratory was central. He himself had recently completed an investigation on muscarinic transmission by acetylcholine; Feldberg and Gaddum were soon to start their study of nicotine transmission by acetylcholine in the superior cervical ganglion. I was studying adrenaline. von Euler and Gaddum had recently discovered substance $\mathbf{P}$ and we continued this work with Gaddum. Marks was studying the mode of action of insulin. These were all central problems at the time and have remained so after all these years.

Dale's laboratory was magnificently organized under the eagle eye of Collison whom one had to inform the evening before if one wanted to do an experiment. Next morning the experiment was perfectly set out by one of his highly trained technicians: but it wasn't advisable to change one's mind then and suggest a different experiment. Dale was the director of the entire National Institute for Medical Research, but he frequently visited, and sometimes experimented, in his own laboratory F4. The laboratory was permeated by his ideas; his conversation was informative and lucid as it remained to the end of his life. He was a keen experimenter himself; I can remember on one occasion fumbling with a scalpel to start a dissection in an anaesthetized 
cat and Dale practically taking the instrument out of my hand and finishing the dissection himself to show me how it ought to be done.

His scientific approach is perhaps best illustrated by one of Dr Feldberg's characteristic stories told at a student dinner. He was comparing the differing approaches of three eminent scientists, Langley, Barcroft and Dale, all of whom he knew well. If Langley had done five experiments, he said, and the sixth gave a divergent result he would do another ten. Barcroft in the same situation would concentrate on the last as being the most interesting. But Dale's style was different. $\mathrm{He}$ believed in working like an astronomer, thinking out and planning the work in greatest detail and finally settling the issue with a few carefully chosen experiments.

I had an accidental glimpse of Dale's approach on an occasion when I visited the National Institute on a trip to London. I found Dale and Feldberg engaged in a fundamental experiment in which they were trying to demonstrate that sweat gland secretion, although anatomically innervated by the sympathetic, was cholinergic. They perfused the footpad of an anaesthetized cat with eserinized Ringer and were going to stimulate the sympathetic chain and use the dorsal muscle of the leech as a test for acetylcholine release. They duly stimulated the sympathetic but could find no evidence of acetylcholine release. On that day Dale was not in the best of tempers and he left the laboratory abruptly. Next day I visited the laboratory again and found out that the experimenters had decided to change their approach in a small but vital respect by doubling the concentration of potassium in the perfusate. This time there was a large contraction of the leech after stimulation of the sympathetic chain: acetylcholine had been released. Dale was happy and jovial and said laughingly 'and if they don't believe it, let them repeat the experiment'. The experiment was of course repeated by the authors themselves, indeed it is recorded that it was repeated four times with identical results, but Dale's facetious remark shows how much store he set by the outcome of even a single experiment, if it was well thought out, and carefully executed.

\section{Contributions to pharmacology}

Dale has made many contributions to pharmacology and I shall select only a few that have particularly influenced future developments.

\section{Adrenaline reversal by ergot}

This was one of Dale's earliest discoveries. It is interesting to read in his semi-autobiographical Adventures in Physiology how at the age of 29, Dale found himself without a permanent academic post and how Henry Wellcome offered him a post in his es-

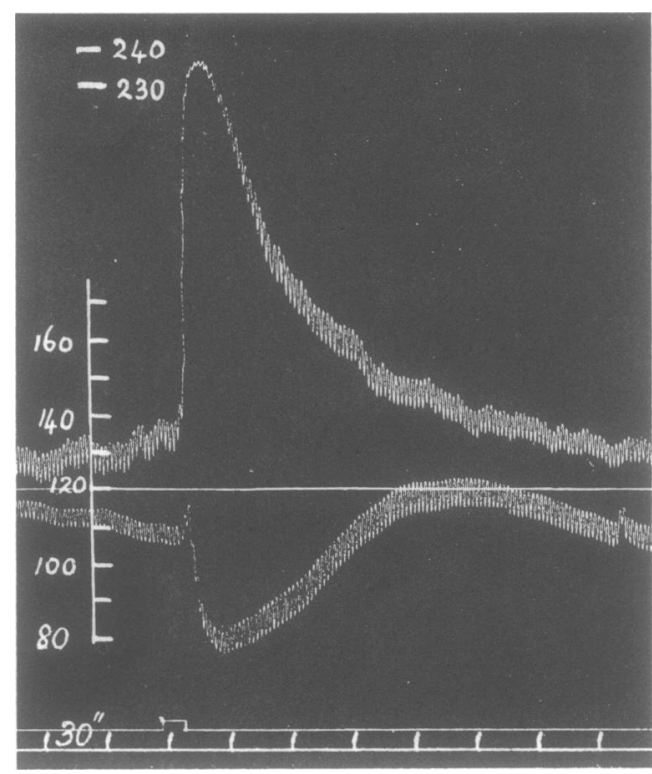

Figure 1 Pithed cat. Carotid blood pressure. Upper curve shows the effect of $0.025 \mathrm{mg}$ of adrenine before, lower curve that of $0.1 \mathrm{mg}$ adrenine after $10 \mathrm{mg}$ of ergotoxine. (From Dale, H.H. (1913). On the action of ergotoxine: with special reference to the existence of sympathetic vasodilators. J. Physiol. Lond., 46, 291-300, reproduced by permission of The Journal of Physiology).

tablishment adding that he hoped he would do work of permanent scientific value there.

His first assignment was an investigation of the pharmacology of ergot of which he soon tired since all he could discover was that all ergot extracts prepared by his friend Barger produced a rise of blood pressure in the spinal cat. Then, by one of his 'greatest strokes of good fortune' he had the opportunity of committing a 'howler' when he was sent a sample of dried suprarenal powder from the factory with a request to test it for adrenaline. He tested it on a cat that had received ergot all day and could get no rise of blood pressure with it, only a fall. So he pronounced it inactive; this was the howler. Next week by another fortunate coincidence-but he adds slyly, perhaps they also wanted to test the competence of their newly-found pharmacologist-he was sent another suprarenal extract and the same sequence of events repeated itself. Dale now became suspicious and investigated the interactions of adrenaline and ergot in a remarkable series of experiments the main outcome of which is summarized in Figure 1 which shows the phenomenon of adrenaline (adrenine) reversal by ergot. Adrenaline alone produced a rise of blood pressure in the spinal cat but after ergot it produced a 
fall. Dale concluded that ergot had paralyzed the myoneural junctions of the sympathetic concerned with motor function, leaving those concerned with inhibition unaffected. In the same paper Dale showed that the cardioaccelerator effect of adrenaline was not, or was much less, antagonized by ergot. The paper thus goes a long way, though by no means the whole way, towards establishing what were later called by Ahlquist the alpha and beta actions of adrenaline. Perhaps the main difference in Dale's approach was that he did not analyze the problem in terms of receptors.

\section{Sympathomimetic amines}

The term sympathomimetic was introduced by Barger and Dale to denote a range of compounds which 'simulate the effects of sympathetic nerves with varying intensity and varying precision'. Their study of over 50 sympathomimetic amines was one of the early comprehensive investigations of the relation between chemical constitution and pharmacological action, a subject which had always interested Dale. Their main conclusions were that the more substances resembled adrenaline in structure the more active they became, and that all sympathomimetic compounds were primary or secondary amines whilst tertiary and quaternary bases had nicotine-like actions.

Retrospectively one of the most interesting aspects of their paper, which was published in 1910, is its discussion of noradrenaline. Dale investigated noradrenaline which was then already obtainable from the Hoechst company under the name arterenol and found that it had greater stimulant and less inhibitory activity than adrenaline and he points out in the discussion that the actions of noradrenaline correspond more closely to sympathetic stimulation than those of adrenaline. He rejects Elliott's earlier suggestion that the similarity between the effects of adrenaline and sympathetic nerves may be due to the latter liberating adrenaline at nerve endings because of the lack of parellelism between adrenaline and sympathetic stimulation; but he fails to conclude that noradrenaline might occur as such in the body and be a better candidate than adrenaline for Elliott's postulated sympathetic transmitter substance. Dale himself marvelled later at his failure to jump to the truth'.

In this connection I can recall when working with Dale in 1933 and finding a consistent discrepancy between physiological and colorimetric estimates of adrenaline content of suprarenal medulla, that it did not seem to occur to either of us that the discrepancy might be due to the adrenal gland containing noradrenaline as well as adrenaline. It remained for the later work by Holtz and von Euler to establish clearly the occurrence of noradrenaline in the suprarenal medulla as well as in postganglionic sympathetic nerves.

\section{Histamine}

Dale was deeply interested in histamine, which he discovered with Barger in ergot extracts and whose pharmacological actions he described almost completely except its action on acid gastric secretion which was described by Popielski.

He was particularly interested in the capillary dilator effect of histamine, which he used as a tool to analyze capillary function under normal and pathological conditions. He considered histamine an important ingredient of 'autopharmacology' and introduced the notion of a 'locally acting chemical stimulant' to distinguish between true hormones in the sense of Bayliss and Starling and substances like histamine whose effects were restricted to the immediate neighbourhood of their liberation.

Dale considered the possibility that the release of histamine or a histamine-like substance might contribute to the physiological regulation of capillary blood flow, reasoning that the liberation of such a principle, as the result of metabolic activity, would provide a perfect fine adjustment of the capillary circulation to the needs of the tissues. But he remained reluctant to accept this 'teleological' argument as evidence and at no point does he in fact suggest that histamine is a physiological capillary regulator.

Dale was similarly cautious in accepting histamine as a cause of traumatic shock, although he had shown with Laidlaw that the injection of large doses of histamine in cats produced a condition of irreversible circulatory collapse due to fall in blood volume caused by a loss of tone of the capillaries, accompanied by an excessive permeability of blood vessels allowing the escape of plasma.

This cautious attitude was due partly to lack of evidence that histamine was a normal constituent of tissues, but even at a later stage, after his own laboratory had shown that histamine could be extracted from tissues, he would go no further than to admit that it might be involved as a capillary dilator in reactions of superficial injury such as Lewis's triple response. Dale's standards of proof were rigorous. Even histamine release in anaphylaxis he would only accept after Feldberg and Dragstedt had produced unequivocal direct evidence for it.

Although Dale failed to establish a physiological role for histamine his papers on histamine are amongst his most instructive, as examples of his scientific style, powers of physiological analysis and range of techniques. They also illustrate the penetrating quality of his discussion and his care in drawing conclusions from experiments.

\section{Theory of neurohumoral transmission}

The neurohumoral theory which Loewi and Dale created produced a fundamental change of outlook in which Dale's studies of acetylcholine have played a 
key role. Acetylcholine was synthesized in the 1890's and in 1906 Hunt and Taveau discovered its strong blood pressure lowering effect. They already considered the possibility that it might be a natural body constituent but this was not proved until much later, when Dale and Dudley extracted it from the spleen. Dale discovered acetylcholine, as he had discovered histamine, in ergot and in 1914 carried out an important investigation of its pharmacological properties. He noted a striking parallelism between the effects of acetylcholine and parasympathetic nerve stimulation and found that the effects of small doses of acetylcholine were readily antagonized by atropine but that larger doses given after atropine produced a nicotine-like stimulation of sympathetic ganglia and the adrenal medulla. These observations induced him to subdivide the actions of acetylcholine into 'muscarine' and 'nicotine' actions with far-reaching consequences for the future.

At that time Dale had not yet formed a clear notion of neurohumoral transmission. In a retrospective lecture he characterized the position around 1914 as follows: 'Two substances were known with actions suggestively reproducing those of the two main branches of the autonomic nervous system: both were very unstable in the body and their actions were consequently of a fleeting character and one of them was already known to occur as a natural hormone. These properties would fit them to act as mediators of autonomic impulses to effector cells if there were any acceptable evidence of their liberation at nerve endings. The actors were named and the parts allotted. A preliminary hint of a plot had indeed been given ten years earlier but had been completely forgotten (Elliott's hint that adrenaline might be the sympathetic transmitter), but only direct and unequivocal evidence could ring up the curtain and this was not to come until 1921'.

In 1921 Otto Loewi began his series of classical experiments on the frog heart which established the concept of neurohumoral transmission. The subsequent work by Dale and his associates was complementary to that of Loewi. It is almost impossible to disentangle the contributions of Loewi and Dale to the humoral theory, so closely are they interwoven. I believe that both are equally responsible. Dale would not have produced the theory without Loewi's brilliant experiments, and Loewi could not have produced it without Dale's deep physiological insight. Whereas Loewi had generated a brilliant general idea, Dale gave it life and substance by applying it to autonomic and somatic nerves and building up an integrated system of neurohumoral transmission in which the muscarinic and nicotinic actions of acetylcholine played a basic role.

The main discoveries of Dale's group, made in rapid succession, can be summarized as follows. Acetylcholine is the chemical transmitter of vagus effects to the stomach (Dale \& Feldberg, 1934a).
Acetylcholine mediates transmission from sympathetic postganglionic nerves to sweat glands (Dale \& Feldberg, 1934b). (In this context Dale suggested the words 'cholinergic' and 'adrenergic' to provide a functional classification of nerve endings.) Acetylcholine transmits the stimulus of splanchnic nerves to the adrenal medulla (Feldberg, Minz \& Tsutzimura, 1933). Acetylcholine transmits the preganglionic stimulus in the superior ganglion (Feldberg \& Gaddum, 1934). Acetylcholine is the transmitter at the motor endplate of striated muscle (Dale, Feldberg \& Vogt, 1936; Brown, Dale \& Feldberg, 1936). Although the idea that the shortlatency nicotinic transmissions at ganglia and the motor endplate are transmitted by acetylcholine was resisted at first by electrophysiologists, the neurohumoral theory became widely accepted by the end of the decade.

The work of Loewi and Dale led to a transformation of physiological and pharmacological thinking. The idea which had persisted since Claude Bernard, that curare blocked motor nerve endings, and the related ideas that adrenaline and pilocarpine stimulated sympathetic and parasympathetic nerve endings and that atropine blocked the latter had to be abandoned. A new pharmacology based on humoral transmission was developed with important consequences for clinical medicine. It now became possible to evolve by rational processes drugs capable of modifying neurohumoral transmission such as the anticholinesterases in myasthenia gravis, tubocurarine in anaesthesia and adrenergic neurone blocking drugs in hypertension. It is of historical interest that Burn \& Dale (1915) showed that tetraethylammonium antagonized the ganglion stimulant effect of tetramethylammonium. Some 30 years later tetraethylammonium was used clinically as the first effective ganglion blocker for the treatment of hypertension.

\section{Anaphylaxis}

Dale's contribution to anaphylaxis was brief and incisive. Once again his initial discovery was made by accident, 'one of my most fortunate accidents' as he called it. Whilst experimenting with guinea-pig isolated uterus he came across a specimen which responded with a maximal contraction to a small dose of horse serum. On enquiry he learned that the guinea-pig was sensitized to horse serum having been usea previously for antitoxin experiments. The finding that an isolated organ taken from a sensitized animal would respond to the specific antigen in the complete absence of serum or blood was the beginning of the cellular theory of anaphylaxis. Soon afterwards Dale found out that Schultz in Washington had independently made similar observations and he considered giving up the work. Fortunately he did not do so because although the reaction itself is rightly credited with both 
their names (it is generally referred to as the SchultzDale reaction in the U.S.A. and as the Dale-Schultz reaction in Britain), Dale's analysis of the underlying mechanism carried the day.

His analysis had the quality of diagrammatic simplicity. He demonstrated that the reaction was highly specific and that it depended on the antibody becoming firmly attached to the cell. He clearly distinguished between desensitization and immunity, defining desensitization as the failure of the sensitized tissue to respond repeatedly to the same antigen whilst immunity, he considered, was due to excess free antibody in the serum capturing the antigen and preventing its access to the sensitized tissue. Immunology has greatly altered since Dale's time and many of his detailed immunological concepts are no longer tenable, but his general conception of cellular anaphylaxis has stood the test of time largely unchanged.

\section{Biological standardization}

Dale said of biological standardization that 'for many years it made a claim on time and thought which I would have willingly given to more fundamental but not, I think, more important research activities'. Their importance lay in three directions. First, it was largely through Dale's insistence on the comparative nature of biological standardization and the necessity for stable standards that reliable samples of insulin, posterior pituitary and digitalis became available to the medical profession. Second, Dale formulated the principles of biological standardization in so lucid a manner that to this day they have formed the basis of teaching the subject. Third, and perhaps most important, was his indirect influence in developing the field of biological assay. He somehow managed to congregate around him or influence a group of mathematically inclined pharmacologists such as Treven, Gaddum and others who established the statistical principles of biological assay. Bioassay has become the basis of all pharmacological measurement in the widest sense and it is largely through the study of bioassay that

\section{References}

BROWN, G.L., DALE, H.H. \& FELDBERG, W. (1936). Chemical transmission of excitation from motor nerve to voluntary muscle. J. Physiol., Lond., 87, 42P.

BURN, J.H. \& DALE, H.H. (1915). The action of certain quaternary ammonium bases. J. Pharmac., 6, 417-438.

DALE, H.H. \& FELDBERG, W. (1934a). The chemical transmitter of vagus effects to the stomach. J. Physiol., Lond., 81, 320-334.

DALE, H.H. \& FELDBERG, W. (1934b). The chemical transmitter of nervous stimuli to the sweat glands of the cat. J. Physiol., Lond., 82, 121-128. statistical measuring techniques have entered pharmacology and medicine. Much of the present emphasis on the quantitative assessment of drug action can be traced back to this small group of fiercely independent workers who were yet all somehow associated with Dale.

\section{Dale's impact}

Dale's most outstanding contribution to pharmacology was undoubtedly neurohumoral transmission because of its general significance, but he has made many special contributions, amongst them discoveries of great importance, only a few of which I have been able to mention. For example he was the first to describe the stimulant action of posterior pituitary extract on the uterus.

It is astonishing how much of Dale's work still stands today. This is due in part, no doubt, to the careful way in which he hedges around his statements - he was known in his youth to rewrite his papers many times-but more basically it is due to the inherent quality of his achievement, its solidity and realism. His ideas have proved eminently fruitful as the present meeting testifies. It is astonishing how Dale's notions of neurohumoral transmission which were originally conceived in terms of the peripheral nervous system, have been transplanted to the central nervous system almost without fundamental modification of his basic concepts.

Some of us here today had the good fortune of knowing Dale personally. I believe that we were all impressed not only by his individual scientific achievements, but by the total impact of his personality, the sweep of his thought. It is perhaps the function of a meeting such as this to try to convey some of this impact to a younger generation to whom Dale represents only a name of a great scientist born 100 years ago.

(Received October 23, 1975)

DALE, H.H., FELDBERG, W. \& VOGT, M. (1936). Release of acetylcholine at voluntary nerve endings. $J$. Physiol., Lond., 86, 353-380.

FELDBERG, W. \& GADDUM, J.H. (1934). The chemical transmitter at synapses in a sympathetic ganglion. $J$. Physiol., Lond., 81, 305-319.

FELDBERG, W., MINZ, B. \& TSUTZIMURA, H. (1933). The mechanism of the nervous discharge of adrenaline. $J$. Physiol., Lond., 80, 15P. 